\title{
PERBEDAAN HASIL BELAJAR MENGGUNAKAN MODEL PEMBELAJARAN HANDS ON ACTIVITY DENGAN MODEL KOOPERATIF TIPE JIGSAW PADA POKOK BAHASAN FOTOSINTESIS KELAS VII SMP NEGERI 12 BATAM
}

\section{LEARNING OUTCOMES DIFFERENCES BY USING HANDS ON ACTIVITY LEARNING MODEL AND COOPERATIVE JIGSAW MODEL ON THE PHOTOSYNTHESIS SUBJECT AT CLASS VII SMPN 12 BATAM}

\author{
Ernawati ${ }^{1}$, Lani Puspita ${ }^{2 *}$, Nurhaty Purnama Sari ${ }^{3}$ \\ ${ }^{123}$ Program Studi Pendidikan Biologi, FKIP, UNRIKA, Batam \\ *Korespondensi : lani.puspita@gmail.com
}

\begin{abstract}
Abstrak
Penelitian ini bertujuan untuk mengetahui perbedaan hasil belajar antara model Hands On Activities (HOA) dengan pembelajaran Jigsaw Model Cooperatif (JMK) pada pokok fotosintesis kelasVII SMP Negeri 12 Batam Tahun Ajaran 2013/2014. Jenis penelitian adalah penelitian eksperimental, dengan populasi terjangkau semua siswa kelas VII yang terdiri dari 7 kelas. Dalam penelitian ini sebagai sampel terpilih kelas VII.5 sebagai kelas HOA dan kelas VII.6 sebagai kelas JMK serta teknik analisis data mengunakan Uji t tingkat kepercayaan 95\% $(\alpha=5 \%)$. Hasil penelitian menunjukkan bahwa rata-rata nilai hasil belajar kelas HOA adalah 80,62 dan kelas JMK adalah 84,67, Uji $t$ menujukkan nilai $t_{\text {hitung }}=2,1>t_{\text {tabel }}=1$,996 maka $\mathrm{H}_{\mathrm{o}}$ ditolak dan $\mathrm{H}_{\mathrm{a}}$ diterima. Kesimpulan ada perbedaan yang signifikan antara hasil belajar siswa menggunakan Hands On Aktivitas dengan Jigsaw Model Koperasi kelas VII subjek fotosintesis SMP Negeri 12 Batam.
\end{abstract}

Kata Kunci: Model Hands On Aktivitas, Model Jigsaw Model Koperasi, Hasil Belajar.

\begin{abstract}
This study aims to determine the learning outcomesdifferences between Hands an Activities (HoA) model and Jigsaw Model Cooperatif (JMC) on photosynthesis subject at class VII SMP Negeri 12 Batam Academic Year 2013/2014. This type of research was experimental with a population all class VII students consisting 7 classes. In this study, HoA selected sample was class VII.5 and VII.6 selected for JMC and data analysis technique used t-test confidence at level 95\% $(\alpha=5 \%)$. The results showed that the class HoA learning outcomes value average was 80.62 and class JMK was 84.67 and t-test analysis showed the $t_{\text {value }}=$ $2.1>t_{\text {table }}=1.996$, so, $H_{o}$ was rejected and $H_{a}$ was accepted. The conclusion, there was a significant difference between student learning ourcomes by using the Hands On Model (HoM) and Jigsaw Cooperative Activities (JMC) on photosynthesis subject at class VII SMP Negeri 12 Batam.
\end{abstract}

Keyword: Hands an Activities (HoA)), Jigsaw Model Cooperatif (JMC), Result Learning

\section{PENDAHULUAN}

Biologi merupakan salah satu cabang ilmu pengetahuan alam yang mempunyai peranan penting bagi ilmu pengetahuan dan teknologi dan agar pembelajaran Biologi dapat berjalan dengan baik sangat diperlukan kreativitas guru dalam mempersiapkan pembelajaran Biologi semenarik mungkin bagi siswa, sehingga dapat meningkatkan 
antusiasme siswa dalam belajar. Bahwa dalam mengajar seorang guru memerlukan kecakapan, pemahaman, inisiatif dan kreatifitas dari pihak guru.

Berdasarkan pengamatan penulis dengan guru dan siswa kelas VII SMP Negeri 12 Batam diketahui bahwa pembelajaran Biologi disekolah tersebut sudah beragam. Proses pembelajaran selama ini yang sudah diterapkan adalah ceramah, tanya jawab, eksperimen dan sesekali melalui diskusi kelompok. Namun sedikit siswa yang mampu berkonsentrasi dalam menerima pelajaran dikarenakan kurangnya persiapan sebelum pembelajaran berlangsung. Kondisi ini menyebabkan tingkat pemahaman siswa terhadap materi pelajaran Biologi belum optimal, akibatnya akan berpengaruh pada pencapaian hasil belajar siswa yang belum maksimal dengan indikasi belum tercapainya hasil belajar sesuai dengan KKM.

Pencapaian hasil belajar Biologi dipengaruhi oleh faktor internal maupun eksternal yang beragam. Model pembelajaran aktif merupakan kegiatan pembelajaran yang dirancang untuk mengaktifkan siswa dalam pembelajaran. Hal ini sejalan dengan yang dikemukakan oleh Silberman (2009) dalam Aprilianti (2013) bahwa pembelajaran yang dapat membuahkan hasil belajar yang berkelanjutan hanyalah kegiatan belajar aktif. Agar kegiatan belajar menjadi aktif, siswa harus menggunakan otak untuk menguji gagasan, memecahkan masalah dan menerapkan apa yang mereka pelajari. Belajar aktif harus gesit, penuh semangat dan bergerak aktif. Melalui model Hands On Activity dan Kooperatif tipe Jigsaw dapat melakukan proses pembelajaran IPA di sekolah tersebut, karena prasarana ruang laboratorium sangat mendukung untuk proses pembelajaran dengan menggunakan dua model ini. Dengan harapan siswa dalam mengikuti pembelajaran IPA bisa menyenangkan juga membuat siswa lebih mampu memahami konsep materi yang diajarkan oleh guru serta memberikan pengaruh atau efek yang diperoleh dari hasil pembelajaran tersebut bisa diaplikasikan dengan kehidupan nyata siswa.

Pada model pembelajaran Hand on Activity dan model Kooperatif Tipe Jigsaw dapat mengajar siswa mampu berinteransi secara positif dengan saling belajar satu sama lain. Siswa mampu menemukan pengalaman nyata yang dialaminya serta siswa sendirilah yang dituntut peran aktif dalam proses belajar mengajar. Salah satu hal yang penting dimiliki oleh siswa dalam hasil belajarnya adalah penguasaan bahan pelajaran. Siswa yang kurang menguasai bahan pelajaran maka dituntut adanya aktivitas dari siswa bukan hanya 
sekedar mengingat, tetapi lebih dari itu yakni memahami, mengaplikasikan, mensintesis dan mengevaluasi bahan pelajaran.

Dari permasalahan yang sudah dijelaskan diatas maka penulis akan melihat perbedaan hasil belajar dengan menggunakan dua model yaitu model pembelajaran Hands on Activity dan model pembelajaran Kooperatif Tipe Jigsaw terhadap hasil belajar biologi siswa kelas VII di SMP Negeri 12 Batam.

\section{METODOLOGI}

Jenis penelitian ini adalah penelitian ekperiment penelitian eksperimen adalah suatu penelitian mengadakan perlakuan terhadap vareiabel penelitian (variabel bebas), dan kemudian mengamati konsekuensi perlakuan tersebut terhadap objek penelitian (variable terikan). Dalam penelitian ini di ambil dua kelas yaitu: kelas eksperimen $\left(\mathrm{X}_{1}\right)$ dan kelas eksperimen $\left(\mathrm{X}_{2}\right)$. Pada kelas eksperimen $\left(\mathrm{X}_{1}\right)$ digunakan model pembelajaran Hands On Aktivitysedangkan kelas eksperimen $\left(\mathrm{X}_{2}\right)$ menggunakan model pembelajaran kooperatif tipe Jigsaw. Model rancangan penelitian yang digunakan adalah Randomizeb Post test only contions Group Design (Riyanto, 2010) digambarkan sebagai berikut:

Tabel 1. Model Rancangan Penelitian

\begin{tabular}{ccc}
\hline Kelas & Perlakuan & Post test \\
\hline Eksperimen & $\mathrm{X} 1$ & $\mathrm{Y} 1$ \\
Eksperimen & $\mathrm{X} 2$ & $\mathrm{Y} 2$ \\
\hline
\end{tabular}

Keterangan :

X1 : Model pembelajaran Hands On Activity

X2 : Model pembelajaran Kooperatif Tipe Jigsaw

Y1 : Post test model pembelajaran Hands On Activity

Y2 : Post test Model pembelajaran Kooperatif Tipe Jigsaw

Variabel dalam penelitian ada 2 (dua) macam, yaitu;

a) Variabel beabas merupakan variabel yang berpegaruh terhadap variabel lain atau perlakuan yang diberikan pada kelas eksperimen. Pada penelitian ini variabel bebasnya adalah :

$\mathrm{X}_{1}$ : Model pembelajaran Hands On Activity.

X2 : Model pembelajaran kooperatif tipe jigsaw.

b) Variabel terikat yaitu variabel yang merupakan akibat yang dipengaruhi oleh variabel bebas. Pada penelitian ini variabel terikatnya adalah 
$\mathrm{Y}_{1}$ : Hasil belajar model pembelajaran Hands On Activity

$\mathrm{Y}_{1}$ : Hasil belajar model pembelajaran kooperatif tipe jigsaw.

Jenis data dalam penelitian ini adalah data primer yang di peroleh langsung dari hasil belajar siswa dalam ranah kognitif. Sumber data dalam penelitian ini adalah siswa kelas VII SMP Negeri 12 Batam yang terpilih sebagai sempel penelitian. Populasi dalam penelitian ini adalah siswa VII SMP Negeri 12 Batam yang terdiri dari 268 siswa, Untuk lebih jelasnya populasi pada penilitian ini dapat di lihat pada Tabel 2.

Tabel 2. Distribusi Populasi Terjangkau Siswa Kelas VII SMPN 12 Batam

\begin{tabular}{ccccc}
\hline \multirow{2}{*}{ NO } & \multirow{2}{*}{ KELAS } & \multicolumn{2}{c}{ JUMLAH SISWA } & \multirow{2}{*}{ TOTAL } \\
& & LAKI-LAKI & PEREMPUAN & \\
\hline 1. & VIII.1 & 20 & 19 & 39 \\
2. & VIII.2 & 14 & 26 & 40 \\
3. & VIII.3 & 20 & 19 & 39 \\
4. & VIII.4 & 19 & 18 & 37 \\
5. & VIII.5 & 17 & 20 & 37 \\
6. & VIII.6 & 19 & 18 & 37 \\
7. & VIII.7 & 30 & 8 & 38 \\
\hline & TOTAL & $\mathbf{1 4 2}$ & $\mathbf{1 2 6}$ & $\mathbf{2 6 8}$ \\
\hline
\end{tabular}

Sampel penelitian adalah kelas VII-5 sebagai kelas eksperimen (X1) dan kelas VII-6 sebagai kelas eksperimen (X2) siswa SMP Negeri. Teknik yang digunakan dalam pengambilan sampel pada penelitian ini adalah Simpel Random Sampling karena pengambilan anggota sampel dari populasi dilakukan secara acak tanpa memperhatikan strata yang ada di dalam populasi (Sugiyono, 2011). Data penelitian dianalisis dengan analisis statistik deskriptif dan analisis statistik inferensial. Analisis statistik deskriptif digunakan untuk menyajikan data setiap kelompok perlakuan dalam distribusi frekuensi dan divisualisasikan dalam bentuk histogram serta Analisis statistik inferensial dilakukan untuk pengujian hipotesis dan generalisasi hasil penelitian. Pengujian hipotesis menggunakan uji anava untuk melihat pengaruh perlakuan. Jika terdapat pengaruh maka dilakukan uji lanjut menggunakan uji t, dengan membandingkan rerata kedua kelompok data menggunakan uji t pada taraf signifikasi $\alpha=0.05 \%$.

\section{PEMBAHASAN}

Data hasil penelitian dilaksanakan setelah proses pembelajaran sesuai perlakuan penelitian. Data diperoleh dari hasil post test atau dua hasil belajar akhir pada kegiatan 
penelitian. Tes akhir menggunakan 25 soal objektif yang diambil dari 50 soal yang telah diuji cobakan di SMPN 12 Batam yang kemampuannya setara dengan kelas sampel penelitian.Pada kelas eksperimen (X1) dan kelas eksperimen (X2) masing-masing tes akhir diikuti oleh 37 siswa. Berdasarkan analisis jawaban siswa pada kegiatan tes akhir diperoleh data nilai rata-rata belajar siswa pada Tabel 3.

Tabel 3. Rekapitulasi Data Diskriptif

\begin{tabular}{lccccccccccc}
\hline Kelas & $\mathbf{N}$ & $\mathbf{X}_{\text {rrt }}$ & $\hat{\mathbf{S}}$ & $\dot{\mathbf{S}}^{2}$ & Median & Modus & $\mathbf{Q}_{\mathbf{1}}$ & $\mathbf{Q}_{\mathbf{3}}$ & $\mathbf{N}_{\text {Min }}$ & $\mathbf{N}_{\text {Mak }}$ & Range \\
\hline VII.5 & 37 & 80,62 & 43,29 & 1859,93 & 77 & 74 & 76 & 91 & 64 & 92 & 28 \\
VII.6 & 37 & 84,67 & 66,66 & 4444,75 & 90 & 86 & 77 & 90 & 64 & 100 & 36 \\
\hline
\end{tabular}

Hasil penelitian diperoleh data hasil belajar siswa pada pokok bahasan fotosintesis dengan menggunakan model pembelajaran Hands On Activity pada kelas VII 5 sebagai kelas eksperimen 1 dengan nilai tertinggi 92, dan nilai terendah 64 dengan jumlah siswa sebanyak 37 siswa. Pada uji normalitas digunakan chi kuadrat lihat Tabel 4;

Tabel 4. Perhitungan uji normalitas pada kelas eksperimen1.

\begin{tabular}{ccccccc}
\hline Interval & $\boldsymbol{f}_{\boldsymbol{o}}$ & $\begin{array}{c}\text { Frekuensi } \\
\text { Relative (\%) }\end{array}$ & $\boldsymbol{f}_{\boldsymbol{h}}$ & $\boldsymbol{f}_{\boldsymbol{o}}-f_{\boldsymbol{h}}$ & $\left(\boldsymbol{f}_{\boldsymbol{o}}-f_{h}\right)^{\mathbf{2}}$ & $\begin{array}{c}\left(\boldsymbol{f}_{\underline{o}}-f_{\underline{h}}\right)^{\mathbf{2}} \\
\boldsymbol{f h}\end{array}$ \\
\hline $64-68$ & 1 & 2,702 & 1 & 0 & 0 & 0 \\
$68-73$ & 1 & 2,702 & 5 & -4 & 16 & 1,6 \\
$74-78$ & 18 & 48,648 & 12,5 & 5,5 & 30,25 & 1,68 \\
$79-83$ & 5 & 13,513 & 12,5 & $-7,5$ & 30,25 & 1,12 \\
$84-88$ & 8 & 21,621 & 5 & 3 & 9 & 1,13 \\
$89-93$ & 4 & 10.810 & 1 & 3 & 9 & 2,25 \\
\hline $\boldsymbol{\Sigma}$ & $\mathbf{3 7}$ & $\mathbf{1 0 0}$ & $\mathbf{3 7}$ & $\mathbf{1}$ & & $\mathbf{7 , 8}$ \\
\hline
\end{tabular}

Berdasarkan Tabel 4 perhitungan uji normalitas pada kelas eksperimen 1 terlihat bahwa dari 37 siswa pada kelas ekperimen 1 memiliki rentang nilai dari 64-68 sebanyak 1 orang , 69-73 sebanyak 1 orang, 74-78 sebanyak 18 orang, 79-83 sebanyak 5 orang, 84-88 sebanyak 8 orang, 89-93 sebanyak 4 orang. Sehingga di peroleh $\mathrm{X}^{2}$ hitung =7,8 dengan taraf signifikan $5 \%$ dan $\mathrm{dk}=6-1=5$ di peroleh $\mathrm{X}$ tabel $=11,070$. Dengan demikian terlihat bahwa $\mathrm{X}^{2}$ hitung $<\mathrm{X}^{2}$ tabel dan dapat di tarik kesimpulan distribusi data nilai hasil belajar siswa melalui pos test dinyatakan normal. 
Tabel 5. Perhitungan uji normalitas pada kelas eksperimen 2.

\begin{tabular}{ccccccc}
\hline Interval & $\boldsymbol{f}_{\boldsymbol{o}}$ & $\begin{array}{c}\text { Frekuensi } \\
\text { Relative (\%) }\end{array}$ & $\boldsymbol{f}_{\boldsymbol{h}}$ & $\boldsymbol{f}_{\boldsymbol{o}}-f_{\boldsymbol{h}}$ & $\left(\boldsymbol{f}_{\boldsymbol{o}}-f_{\boldsymbol{h}}\right)^{\mathbf{2}}$ & $\begin{array}{c}\left(\boldsymbol{f}_{\boldsymbol{o}}-\boldsymbol{f}_{\boldsymbol{h}}\right)^{\mathbf{2}} \\
\boldsymbol{f h}\end{array}$ \\
\hline $64-70$ & 2 & 3,404 & 1 & 1 & 1 & 1 \\
$71-76$ & 4 & 10,808 & 5 & -1 & 1 & 0,2 \\
$77-83$ & 9 & 24,318 & 12,5 & $-3,5$ & 12,25 & 0,98 \\
$84-89$ & 13 & 35,126 & 12,5 & 0,5 & 0,25 & 0,02 \\
$90-96$ & 6 & 16,212 & 5 & 1 & 1 & 0,2 \\
$97-103$ & 3 & 8,106 & -1 & 2 & 4 & 4 \\
\hline $\boldsymbol{\Sigma}$ & $\mathbf{3 7}$ & $\mathbf{1 0 0}$ & $\mathbf{3 0}$ & $\mathbf{1}$ & & $\mathbf{6 , 4}$ \\
\hline
\end{tabular}

Berdasarkan hasil pada tabel 5 yang sudah di tabulasikan dalam distribusi frekuensi terlihat bahwa dari 37 siswa pada kelas eksperimen 2 memiliki nilai dari 64-70 sebanyak 2 orang, 71-76 sebanyak 4 orang, 77-83 sebanyak 9 orang, 84-89 sebanyak 13 orang, 90-93 sebanyak 6 orang, dan 93-100 sebanyak 3 orang sehingga di peroleh $\mathrm{X}$ hitung $=6,4$ dengan taraf signifikan $5 \%$ dan $\mathrm{dk}=6-1=5$ di peroleh $\mathrm{X}$ tabel $=11,070$, dengan demikian terlihat bahwa $\mathrm{X}^{2}$ hitung $\mathrm{CX}^{2}$ tabel dapat di tarik kesimpulan distribusi data nilai hasil belajar siswa pada kelas eksperimen 2 ditingkatkan berdistribusi normal.

Tabel 6. Rekapitulasi Uji Normalitas Data Hasil Belajar Kelas Eksperimen 1 dan Eksperimen 2

\begin{tabular}{ccccc}
\hline Variabel & $\mathbf{N}$ & $\begin{array}{c}\mathbf{X}^{2} \mathbf{h i t u n} \\
\mathbf{g}\end{array}$ & $\mathbf{X}^{2}$ tabel & Keterangan \\
\hline Hasil belajar kelas eksperimen 1 & 37 & 7,8 & 11,070 & Normal \\
\hline Hasil belajar kelas eksperimen 2 & 37 & 6,4 & 11,070 & Normal \\
\hline
\end{tabular}

Hasil uji Homogenitas diketahui bahwa varian (kuadrat dari simpangan baku) terbesar $=2400,1081$ dan terkecil $=43,2973$. jadi $\mathrm{F}$ hitung $=2400,1081: 43,2973=1,53$. Harga Fhitung tersebut kemudian dibandingkan dengan $\mathrm{F}$ tabel dengan dk Pembilang = $37-1$ dan dk penyebut (37-1). Berdasarkan dk pembilang $=36$ dan penyebut $=36$ dapat dilihat pada lampiran dengan taraf kesalahan 5\% maka harga $\mathrm{F}$ tabel $=1,72$ (harga antara pembilang 36 dan 40$)$. Ternyata harga $F$ hitung lebih kecil dari $F$ tabel $(1,53<1,72)$ dengan demikian berarti varian homogen. 
Tabel 7. Rekapitulasi Uji Homogenitas Data Hasil Belajar Kelas Eksperimen 1 dan 2

\begin{tabular}{cccccc}
\hline No & Kelas & Varian & $\mathrm{F}_{\text {hitung }}$ & $\mathrm{F}_{\text {tabel }}$ & Kesimpulan \\
\hline 1 & Eksperimen 1 & 43,297 & 1,53 & 1,72 & \\
2 & Eksperimen 2 & 66,669 & & & Homogen \\
\hline
\end{tabular}

Dari hasil perhitungan uji prasyarat analisis data, ternyata $\mathrm{F}$ hitung lebih kecil dari F tabel $(1,53<1,72)$ dengan demikian dapat disimpulkan bahwa data kelas eksperimen 1 dengan menggunakan model pembelajaran Hand On Actvity dan kelas Eksperimen 2 dengan menggunakan model Kooperatif tipeJigsaw yang dianalisi sama dan homogen maka prasyarat untuk pengujian hipotesis telah terpenuhi.

Tabel 8. Rekapitulasi Hasil Uji Hipotesis

\begin{tabular}{ccccccccc}
\hline Kelas & $\mathrm{N}$ & $\mathrm{X}_{\text {rerata }}$ & Varian & $\mathrm{T}_{\text {Hitung }}$ & $\mathrm{T}_{\text {Tabel }}$ & Nilai $\alpha$ & $\mathrm{k}$ & $\mathrm{Ket}$ \\
\hline Ekspm.1 & 37 & 80,621 & 43,297 & 2,1 & 1,996 & 0,05 & 72 & $\mathrm{H}_{0}$ \\
Ekspm.2 & 37 & 84,675 & 66,669 & & & & & ditolak \\
\hline
\end{tabular}

Berdasarkan uji tdiperoleh $\mathrm{t}_{\text {hitung }}=2,1$ dan $\mathrm{t}$ tabel $=1,996$ karena $\mathrm{t}$ hitung $>$ dari $\mathrm{t}$ sehingga Ho ditolak dan Ha diterima. Ho ditolak yang berarti ada perbedaan antara hasil belajar siswa yang menggunakan model pembelajaran Hand On Activity dengan kooperatis tipe jigsaw pada pokok bahasan fotosintesis. Dengan demikian apabila $t_{\text {hitung }}>t_{\text {tabel }}$ maka hipotesis penelitian $\left(\mathrm{H}_{0}\right)$ ditolak dan $(\mathrm{Ha})$ diterima. Hal ini berarti ada perbedaan dari hasil belajar menggunakan model pembelajaran Hand On Activity dengan model pembelajaran kooperatif tipe jigsaw pada pokok bahasan fotosintesis kelas VIISMP Negeri 12 Batam.

Berdasarkan hasil tes akhir kedua kelas eksperimen setelah diberikan perlakuan dengan menggunakan model pembelajaran yang berbeda diperoleh hasil yang baik. Ratarata hasil belajar siswa menggunakan Hand On Activity menjadi 80,62 dan rata-rata hasil belajar siswa menggunakan pembelajaran kooperatif tipe jigsaw 84,64. Berdasarkan hasil tersebut terlihat bahwa hasil belajar siswa dengan menggunakan model pembelajaran Hands On Activity dan Kooperatif tipe Jigsaw mengalami peningkatan. Dengan diketahuinya besar nilai dari uji t dapat disimpulkan bahwa ada perbedaan antara hasil belajar siswa yang menggunakan model pembelajar Hands On Activity dengan kooperatif tipe jigsaw. Dengan demikian apabila $t_{\text {hitung }}>t_{\text {tabel }}$ maka hipotesis penelitian $\left(\mathrm{H}_{0}\right)$ ditolak dan (Ha) diterima. Hal ini berarti terdapat perbedaan dari hasil belajar menggunakan 
model pembelajaran Hands On Activity dengan model pembelajaran kooperatif tipe jigsaw pada pokok bahasan fotosintesis. Hal ini menunjukan bahwa model pembelajaran Hands On Activity dan kooperatif tipe jigsaw memberikan dampak positif terhadap hasil belajar biologi siswa kelas eksperimen 1 dan kelas eksperimen 2.

Tabel 8. Ketuntasan Hasil Belajar Siswa Sebelum Menggunakan Model Pembelajaran

\begin{tabular}{cccccccc}
\hline & Hands on Activity VII.5 & \multicolumn{4}{c}{ Kooperatif tipe Jigsaw VII.6 } \\
\hline Tuntas & Persen & Tdk Tnts & Persen & Tuntas & Persen & Tdk Tnts & Persen \\
24 & $64,8 \%$ & 13 & $35,2 \%$ & 23 & $62,2 \%$ & 14 & $37,8 \%$ \\
\hline
\end{tabular}

Berdasarkan gambar diatas Nilai Ketuntasan siswa model pembelajaran Hands on Activity adalah siswa yang mendapat nilai tuntas berjumlah 24 orang dari 37 siswa, sehingga memperoleh $65 \%$ dari jumlah keseluruhan siswa, sedangkan siswa yang tidak tuntas berjumlah 13 orang dari 37 siswa sehingga memperoleh $35 \%$.

Pada pembelajaran Kooperatif tipe Jigsaw adalah siswa yang mendapat nilai tuntas berjumlah 23 orang dari 37 siswa, sehingga memperoleh $62 \%$ dari jumlah keseluruhan siswa, sedangkan siswa yang tidak tuntas berjumlah 14 orang dari 37 siswa sehingga memperoleh $38 \%$.

Tabel 9. Ketuntasan Hasil Belajar Siswa Sesudah Menggunakan Model Pembelajaran

\begin{tabular}{cccccccc}
\hline & Hands on Activity VII.5 & \multicolumn{4}{c}{ Kooperatif tipe Jigsaw VII.6 } \\
\hline Tuntas & Persen & Tdk Tnts & Persen & Tuntas & Persen & Tdk Tnts & Persen \\
27 & $72,5 \%$ & 10 & $27,5 \%$ & 30 & $68,2 \%$ & 14 & $31,8 \%$ \\
\hline
\end{tabular}

Berdasarkan gambar diatas Nilai Ketuntasan hasil belajar siswa kelas VII5 dan VII6 model pembelajaran Hands on Activity adalah siswa yang mendapat nilai tuntas berjumlah 27 orang dari 37 siswa, sehingga memperoleh $75 \%$ dari jumlah keseluruhan siswa, sedangkan siswa yang tidak tuntas berjumlah 10 orang dari 37 siswa sehingga memperoleh 27\%.Pada pembelajaran Kooperatif tipe Jigsaw adalah siswa yang mendapat nilai tuntas berjumlah 30 orang dari 37 siswa, sehingga memperoleh $82 \%$ dari jumlah keseluruhan siswa, sedangkan siswa yang tidak tuntas berjumlah 7 orang dari 37 siswa sehingga memperoleh $18 \%$.

Dari hasil test yang diperoleh, masih terdapat beberapa siswa yang belum tuntas dalam proses pembelajaran. Hal ini di sebabkan oleh beberapa factor yang menjadi 
kendala selama penelitian berlansung. Kendala tersebut ada yang berasal dari diri siswa,peneliti maupun dari proses pelaksaannya. Kendala yang berasal dari diri siswa antara lain mereka menganggap bahwa pelajaran biologi sulit di pahami sehingga ada sebagian siswa yang tidak memperhatikan dan bermain saat peneliti menerangkan pelajaran. Dalam hal ini peneliti berusaha mengajak siswa untuk dapat memperhatikan dan mendengarkan saat guru menerangkan, peneliti juga memberikan arahan, bimbingan supaya siswa biasa menganggap Biologi itu penting dan mudah untuk di pelajari jika punya niat untuk mempelajarinya.

Peneliti menyadari dalam melaksakan Hands On Activity dan kooperatif tipe jigsaw banyak terdapat kekurangan dan kelemahan. Tetapi penelitian yang sudah peneliti lakukan sudah dapat dikatakan lebih baik yang dapat di lakukan dari hasil belajar siswa jadi menigkat. Peneliti mengharapkan nantinya akan ada peneliti yang lebih baik melaksanakan penelitian yang berhubungan dengan penggunaan model pembelajaran Hands On Activity dan kooperatif tipe Jigsaw ini dalam pembelajaran biologi, guna meningkatkan hasil belajar Biologi siswa dan memenuhi ketentuan belajar secara kelompok, yaitu mengalokasikan waktu seefisien mungkin serta dapat mengelola kelas dengan baik.

\section{KESIMPULAN}

Berdasarkan hasil penelitian maka dapat diambil kesimpulan bahwa Hasil Belajar Biologi siswa yangmenggunakan kooperatif tipe jigsaw lebih baik dari pada hasil belajar Biologi siswa yang menggunakan pembelajaran Hands On Activity. Hal ini terbukti dengan lebih tingginya nilai rata-rata skor hasil belajar Biologi siswa kelas eksperimen 2, yaitu 84,67 sedangankan kelas eksperimen 1, yaitu 80,62. Hasil uji-t diperoleh nilai $t_{\text {hitung }}=$ 2,1 dan $t_{\text {tabel }}=1,996$ karena $t_{\text {hitung }}>$ dari $t_{\text {tabel }}$ sehingga Ho ditolak dan Ha diterima, dapat disimpulkan bahwa ada perbedaan yang signifikan antara hasil belajar siswa menggunakan model pembelajaran Hands On Activity dengan kooperatif tipe jigsaw pada pokok bahasan fotosintesis. Secara umum penggunaan model Hands On Activity dan kooperatif tipe jigsaw sangat dipengaruhi dalam hal hasil belajar siswa walaupun perbedaannya tidak signifikan serta dapat merangsang minat belajar siswa untuk mencapai prestasi siswa. 


\section{REFERENSI}

Arikunto, S. 2008. Dasar - Dasar Evaluasi Pendidikan..Jakarta: Bumi Aksara.

BNSP, 2006. Standar Isi Untuk Satuan Pendidikan Dasar dan Menengah. Jakarta: BNSP.

Hardonto, S.K.2003. Pembelajaran Sains Kontekstual. Makala dalam Seminar Nasional Exchange Experience dengan thema pembelajara MIPA Kntekstual Menyongsong Implementasi Kurikulum berbasis Kompentensi.9 Juli 2013Di FMIPA UM.

Hamalik, O .2011. Proses Belajar Mengajar. Jakarata: Bumi Aksara.

Ilmu Pengetahuan Alam, 2013. Kementrian Pedidikan dan kebudayaan Jakarta Kurikulum, 2013.

Rusman, 2013.Model Model Pembelajaran Mengembangkan Profesional Guru. Jakarta : Rajawali Pers,2013.

Soubari, 2006.Implementasi Model Cooperative Learning Tipe Jigsaw untuk Meningkatkan Prestasi Belajar Siswa.

Sugiyono, 2011.Statistik untuk penelitain.Bandung : Alfabeta.

Sudjana, 2005. Metoda Statistika. Bandung: Transito. 